\title{
DETEKSI DAN ANALISA GANGGUAN TEGANGAN BERBASIS MIKROKONTROLER ARDUINO UNO R3 dan LABVIEW
}

\author{
Suminto \\ Prodi Teknik Elektro FT UNPAM \\ Jl. Raya Puspitek No.23, Buaran, Serpong, Kota Tangerang Selatan, Banten 15310, Indonesia \\ E-mail : dosen00944@unpam.ac.id
}

\begin{abstract}
ABSTRAK
Semakin meningkatnya konsumsi energi listrik membuat pasokan listrik dari PLN terkadang tidak stabil dan terkadang terjadi pemadaman bergilir. Gangguan tegangan yang terjadi ini tidak mudah untuk diprediksi kapan waktunya. Alat ukur yang dapat mendeteksi di pasaran harganya masih relative maha. Oleh karena itu dikembangkan alat pendeteksi gangguan tegangan PLN baik karena adanya beban induktif, kapasitif ataupun resistif yang dapat terdeteksi secara real time dan dapat ter-record di dalam harddisk. Metoda penelitian ini adalah membuat alat pendeteksi tegangan menggunakan Mikrokontroles Arduino uno R3 yang terintregrasi dengan LABVIEW. Recording dilakukan pada titik terakhir sambungan PLN dengan beban dan tanpa tambahan beban. Penelitian menunjukkan bahwa rata-rata nilai tegangan tanpa tambahan beban $=216.74$ Volt, beban induktif $=208.38$ Volt, beban kapasitif $=211.25$ Volt, beban resistif $=210.95$ Volt. Dari hasil pengukuran tersebut didapat beban induktif sangat berpengaruh terhadap terjadinya penurunan tegangan. Data yang yang diterima dapat diproses melalui output sesuai dengan perintah yang diinginkan secara continue dan real time.

Kata kunci: ARDUINO UNO R3, GANGGUAN TEGANGAN dan LABVIEW.
\end{abstract}

\begin{abstract}
DETECTION AND ANALYSIS OF INTERFERENCE VOLTAGE microcontroller ARDUINO UNO R3 and LABVIEW. Increasing electricity consumption makes electricity from PLN sometimes unstable and sometimes blackouts occur. The voltage disruption is not easy to predict when the time. Measuring tools that can track market prices are still high. Thus the detection of PLN voltage interference devices is either due to inductive, capacitive or detectable loads that can be detected in real time and can be recorded on hard disk. This research method is to create a voltage detector using Arduino uno R3 Microcomputer which is integrated with LABVIEW. The recording is done at the last point of the PLN connection with the load and no additional load. The study shows that the rated voltage without additional load $=216.74$ Volt, inductive load $=208.38$ Voltage, capacitive load $=211.25$ Volt, resistive load $=210.95$ Volt. From the measurement result obtained by inductive load very influence to the occurrence of voltage decrease. The received data can be processed through the output in accordance with the desired command to continue and real time..
\end{abstract}

Keywords: ARDUINO UNO R3, INTERFERENCE VOLTAGE and LABVIEW

\section{PENDAHULUAN}

\section{$\mathrm{K}$}

emajuan teknologi dalam dunia industri

berkembang dengan pesat, pesatnya industri tersebut membuat konsumsi energi listrik juga semakin meningkat. Semakin meningkatnya konsumsi energi listrik membuat pasokan listrik dari PLN terkadang tidak stabil bahkan di wilayah tertentu terkadang PLN melakukan pemadaman secara bergilir. Terkadang suplai listrik dari PLN tegangan yang kirim ke konsumen tidak sesuai standar yang diberikan. Saat beban puncak tegangn dari PLN menjadi 
berkurang dan saat beban sedikit tegangn dari PLN terkadang melebihi standar yang ada. Hal tersebut bisa membuat peralatan elektronik mengalami kerusakan. Dan bila gangguan tersebut sering terjadi akan membuat konsumen merugi.

Disisi lain perkembangan teknologi juga membawa dampak positif. Semakin maju teknologi juga semakin banyak pilihan bagi para konsumen untuk melakukan inovasi terhadap peralatan yang dapat digunakan untuk membackup bila tegangn dari PLN mati.

Mikrokontroler dan Labview digunakan sebagai alat pendeteksi terjadinya naik dan turunya tegangan, karena data yang didapatkan akan akurat dan data yang diterima dapat langsung diproses melalui output sesuai dengan perintah yang diinginkan. Dalam kehidupan sehari-hari konsumen tidak menyadari jika terjadi gangguan tegangan dan kapan terjadinya gangguan. Yang di rasakan konsumen hanya listrik tiba-tiba padam dan tidak tahu penyebabnya. Bila dalam dunia industri terjaganya pasokan energi listrik akan mengurangi biaya akibat stopnya proses produksi. Dan bila proses produksi tetap bisa berjalan maka perusahaan akan mendapatkan untung seperti target yang di inginkan.

Dari latar belakang yang telah diungkapkan tersebut diperoleh permasalahan bagaimana cara mendeteksi ganguan tegangan dari PLN secara akurat, bagaimana cara mengetahui kapan terjadinya gangguan tegangan dari PLN yang diterima secara continue dan real time, dan bagaimana cara mengetahui perbedaan gangguan tegangan yang di sebabkan karena beban Induktif, Kapasitif dan Resistif .

Dari permasalahan ini peneliti ingin melakukan penelitian tentang nilai tegangan yang ada untuk menghindari kerugian akibat penerimaan tegangan yang tidak stabil.

\section{TEORI}

\subsection{Definisi Mikrokontroler}

Mikrokontroller adalah suatu chip cerdas yang dapat digunakan sebagai pengontrol utama sistem elektronika, misalnya system pengukur suhu digital (thermometer digital), sistem keamanan rumah, sistem kendali mesin industri, robot penjinak bom, dan lainlain. Hal ini dikarenakan didalam chip tersebut sudah ada unit pemroses, memori
ROM (Read Only Memory), RAM (Random Access Memory), I/O, dan fasilitas pendukung lainnya.[1]

Mikrokonktroler digunakan dalam produk dan alat yang dikendalikan secara automatis, seperti sistem kontrol mesin, remote controls, mesin kantor, peralatan rumah tangga, alat berat, dan mainan. Dengan mengurangi ukuran, biaya, dan konsumsi tenaga dibandingkan dengan mendesain menggunakan mikroprosesor memori, dan alat input output yang terpisah, kehadiran mikrokontroler membuat kontrol elektrik untuk berbagai proses menjadi lebih ekonomis.[2] Dengan penggunaan mikrokontroler ini maka :

1. Sistem elektronik akan menjadi lebih ringkas

2. Rancang bangun sistem elektronik akan lebih cepat karena sebagian besar dari sistem adalah perangkat lunak yang mudah dimodifikasi

3. Pencarian gangguan lebih mudah ditelusuri karena sistemnya yang kompak

Agar sebuah mikrokontroler dapat berfungsi, maka mikrokontroler tersebut memerlukan komponen eksternal yang kemudian disebut dengan sistem minimum. Untuk membuat sistem minimal paling tidak dibutuhkan sistem clock.

\subsection{Arduino Uno R3}

Arduino Uno adalah sebuah rangkaian yang dikembangkan dari mikrokontroller berbasis ATmega328. Arduino Uno memiliki 14 kaki digital input / output, dimana 6 kaki digital diantaranya dapat digunakan sebagai sinyal PWM (Pulse Width Modulation). Sinyal PWM berfungsi untuk mengatur kecepatan perputaran motor. Arduino Uno memiliki 6 kaki analog input, kristal osilator dengan kecepatan jam $16 \mathrm{MHz}$, sebuah koneksi USB, sebuah konektor listrik, sebuah kaki header dari ICSP, dan sebuah tombol reset yang berfungsi untuk mengulang program.[3]

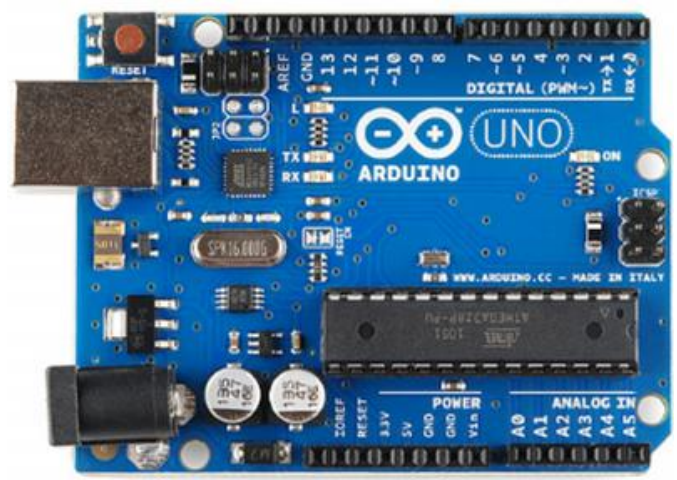

Gambar 1. Board Arduino ATmega328 Sumber: [2] 
Arduino adalah merupakan sebuah board minimum system mikrokontroler yang bersifat open source. Didalam rangkaian board arduino terdapat mikrokontroler AVR seri ATMega 328 yang merupakan produk dari Atmel.

Arduino memiliki kelebihan tersendiri disbanding board mikrokontroler yang lain selain bersifat open source, arduino juga mempunyai bahasa pemrogramanya sendiri yang berupa bahasa $\mathrm{C}$. Selain itu dalam board arduino sendiri sudah terdapat loader yang berupa USB sehingga memudahkan kita ketika kita memprogram mikrokontroler didalam arduino. Sedangkan pada kebanyakan board mikrokontroler yang lain yang masih membutuhkan rangkaian loader terpisah untuk memasukkan program ketika kita memprogram mikrokontroler. Port USB tersebut selain untuk loader ketika memprogram, bisa juga difungsikan sebagai port komunikasi serial. Arduino menyediakan 20 pin $\mathrm{l} / \mathrm{O}$, yang terdiri dari 6 pin input analog dan 14 pin digital input/output. Untuk 6 pin analog sendiri bisa juga difungsikan sebagai output digital jika diperlukan output digital tambahan selain 14 pin yang sudah tersedia. Untuk mengubah pin analog menjadi digital cukup mengubah konfigurasi pin pada program. Dalam board kita bisa lihat pin digital diberi keterangan $0-13$, jadi untuk menggunakan pin analog menjadi output digital, pin analog yang pada keterangan board 0-5 kita ubah menjadi pin 14-19. dengan kata lain pin analog 0 5 berfungsi juga sebagi pin output digital 1416.[2]

Sifat open source arduino juga banyak memberikan keuntungan tersendiri untuk kita dalam menggunakan board ini, karena dengan sifat open source komponen yang kita pakai tidak hanya tergantung pada satu merek, namun memungkinkan kita bisa memakai semua komponen yang ada dipasaran.[3]

\subsection{Transformator (Trafo)}

Transformator adalah komponen elektronika yang digunakan untuk mentranfer energy dari suatu sircuit ke surcuit lain menggunakan induksi magnet Atau suatu peralatan yang digunakan untuk menaikkan atau menurunkan tegangan arus bolak-balik. Satu lagi aplikasi yang sangat penting dari induksi elektromagnetik adalah transformator, yang sering juga disebut trafo. Sebagai contoh, jika kita hendak mengisi aki yang sudah habis, dibutuhkan transformator untuk peralatan charger yang mengubah tegangan listrik di rumah dari 220 Volt AC menjadi sekitar 12 volt AC yang kemudian diubah lagi menjadi 12 volt DC dengan penyearah.[7]

\subsection{Transformator Ideal}

Pada transformator ideal, tidak ada energi yang diubah menjadi bentuk energi lain di dalam transformator sehingga daya listrik pada kumparan skunder sama dengan daya listrik pada kumparan primer. Atau dapat dikatakan efisiensi pada transformator ideal adalah 100 persen. untuk transformator ideal berlaku persamaan sebagai berikut :[6]

$$
=\frac{P}{P} \times 100 \%
$$

$=$ efisiensi transformator

$\mathrm{P}_{\mathrm{s}}=$ daya listrik kumparan sekunder

$\mathrm{P}_{\mathrm{p}}=$ daya listrik kumparan primer

\subsection{LabVIEW}

Program LabVIEW dapat disebut juga Virtual Instrument, atau VI, karena menampilkan dan mengoperasikan contoh bentuk instrumentnya, seperti osciloskop dan multimeter. LabVIEW meliputi pengaturan dari tool untuk mendapatkan, menganalisis, menampilkan, dan mengumpulkan data, lebih baik menggunakan tool untuk membantu anda mencari dan memecahkan masalah pengkodean anda. VI LabVIEW berisi tiga bagian utama-front panel, blok diagram, dan icon dan connector pane. Pada LabVIEW, anda sebagai user interface, atau front panel, dengan control dan indicator. Kontrolnya merupakan knob, push button, dial, dan perintah input devicenya. Indikatornya merupakan grafik, LED, dan perintah tampilan. Setelah anda sebagai pengguna interfacenya, anda menambakan kode menggunakan VI dan struktur untuk control pada objek front panelnya. Blok diagram berisi kodenya. Pada beberapa kondisi, blok diagram menyerupai flowchart.[10]

$$
\text { Kegunakan LabVIEW untuk }
$$
menghubungkannya dengan hardware seperti menambahkan, melihat, dan menggerakkan kontrol data device, dan device GPIB, PXI, VXI, $R S-232$, dan RS-485. LabVIEW juga dapat membangun untuk menghubungkan aplikasi anda untuk Web mengunakan LabVIEW Web Server dan software standarnya seperti jaringan TCP/IP dan ActiveX.[10]

Dengan menggunakan LabVIEW, anda dapat membuat percobaan dan pengukuran, penambahan data, control instrument, datalogging, analisi instrument, dan hasil aplikasi yang dihasilkannya. Anda juga dapat membuat stand-alone executable dan shared libraries, sama DLL, karena LabVIEW tersusun dari 32bit[10] 


\subsection{Front Panel Toolbar LabVIEW}

Berikut ini adalah tampilan front panel toolbar pada labview tombol-tombol toolbar tersebut digunakan untuk menjalankan dan merubah VI. berikut ini terlihat pada front panel.

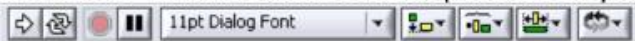

Gambar 2. Tampilan front panel toolbar Sumber:[10]

\subsection{Blok Diagram Toolbar Labview}

Saat anda menjalankan $\mathrm{VI}$, tombol terlihat pada toolbar blok diagram bahwa anda dapat menggunakannya untuk debug VI. Toolbar berikut ini terlihat pada gambar 2.15.[10]

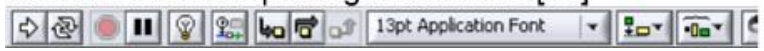

Gambar 3. Tampilan blok diagram toolbar labview Sumber:[10]

\section{METEDOLOGI}

\section{$3.1 \quad$ Perancangan Gangguan Tegangan Pendeteksi Arduino Uno R3 dan Labview.}

Berikut adalah hal yang harus dilakukan dalam membuat rancangan alat pendetaksi tegangan berbasis arduino yang terintregasi dengan labview::

1. Menyiapkan perangkat keras berupa arduino, dalam hal ini yang di gunakan adalah arduino uno R3. Yang dinilai cukup mengkafer kebutuhan dalam menjalankan progran dan cukup untuk mencari data yang ingikan.

2. Pada laptop atau computer diinstal program Labview. Dalam hal ini Labview yang digunakan adalah Labview 2015 karena dinilai lebih mudah untuk di sinkronisasikan dengan arduino uno R3.

3. Pada Laptop atau computer diinstal NI-VISA, hal tersebut harus dilakukan agar perangkat arduino dan Labview bisa dapat berkomunikasi dengan baik.

4. Mengisi program pada arduino agar arduino tersebut bisa diberi program melalui Labview.

\subsection{Perancangan Hardware Alat Pendeteksi gangguan Tegangan Berbasis Mikrokontroler dan Labview}

Dalam melakukan penelitian tersebut diperlukan perangkat keras, dan berikut adalah spesifikasi perangkat keras yang digunakan untuk mendeteksi tegangan dari PLN.

- Trafo step down

- Dioda
- Arduino UNO R3 beserta Kabel konektifitas data Aduino dengan Laptop.

- Laptop / PC

- Lampu LED

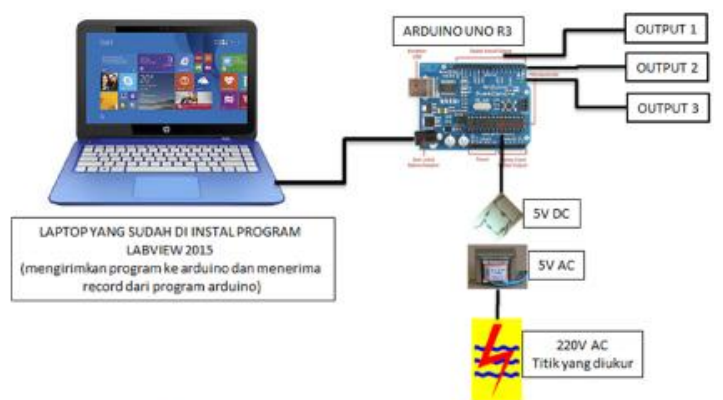

Gambar 4. Rangkaian alat pendeteksi gangguan tegangan berbasis mikrokontroler Arduino UNO R3 dan Labview

Prinsip kerja rangkain pada gambar 3 adalah sebagai berikut:

1. Tegangan dari PLN 220VAC dan dimasukan ke trafo stepdown untuk kemudian diturunkan menjadi 4,5 5VAC.

2. Trafo stepdown akan menurunkan tegangan menjadi 4,5 5VAC yang kemudian dirubah menjadi 4,5 5VDC oleh jembatan dioda.

3. Tegangan $4,5 \sim 5 \mathrm{VDC}$ dari dioda dialirkan ke input analog pada arduino untuk selanjutnya tegangan tersebut diolah oleh arduino.

4. Arduino akan merekan data tengan yang masuk, dan data tersebut akan tersimpan dalam memori PC atau laptop yang digunakan untuk merekam data tersebut.

5. Jika tegangan dari PLN $220 \mathrm{~V}$ maka trafo akan mengeluarkan tegangan $5 \mathrm{~V}$ tegangan tersebut akan diolah oleh arduino untuk menyalakan output pada arduino sesuai dengan program yang tersimpan. Untuk mempermudah pemahaman pembacaan kerja pada output arduino dapat dilihat pada tabel berikut.

\subsection{Perancangan Software Alat Pendeteksi gangguan Tegangan Berbasis Mikro kontroler terintregasi dengan Labview}

Dalam perancangan software alat pendeteksi gangguan tegangan berbasis mikrokontroler ini prinsip dasarnya adalah mendeteksi nilai tegangan yang sebelumnya analog menjadi digital. Dan data digital tersebut dirubah ke dalam bentuk nilai atau angka dalam tegangan. Dan selanjutnya data atau angka 
digital tersebut akan di simpan dalam bentuk file excel dan di simpan ke dalam hardisk komputer.

3.1.1 Pembuatan program pada labview untuk arduino.

Pembuatan program rangkaian pendeteksi tegangan berbasis mikrokontroler yang terintegrasi dengan labview adalah seperti gambar 3.8.

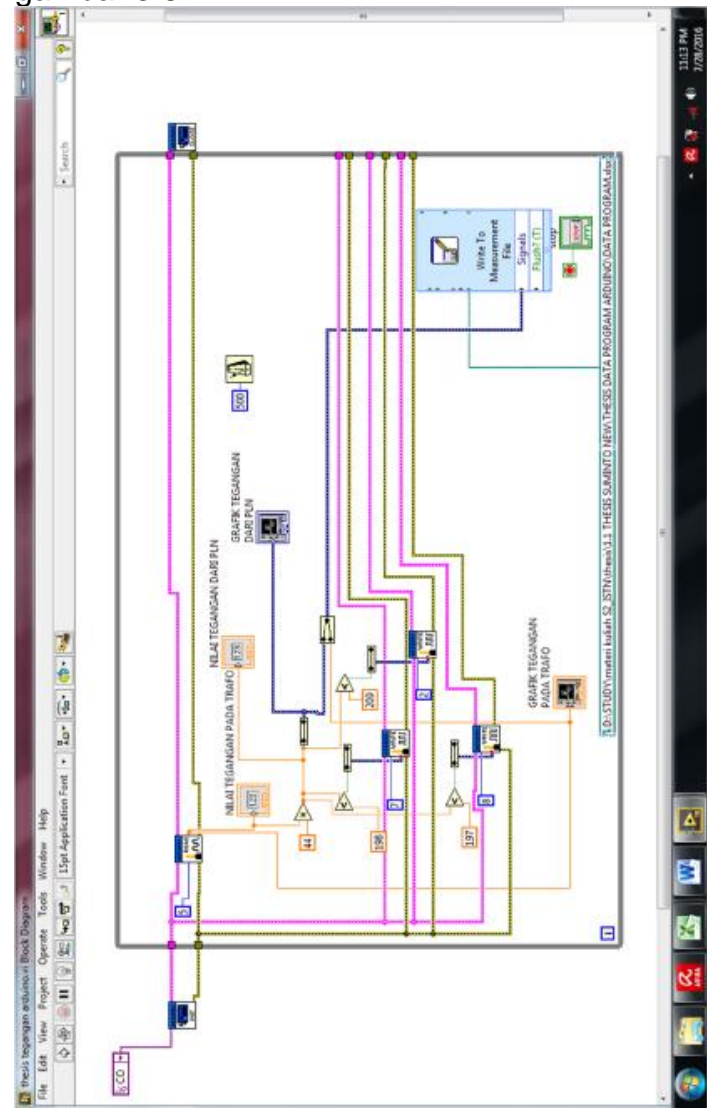

Gambar 5. Tampilan program pendeteksi gangguan tegangan berbasis arduino uno R3dan Labview

Sedangkan untuk panel front digunakan sebagai tampilan display saat program tersebut menjalankan perintah yang diinginkan. Untuk program pada gambar tampilan view nya saya membuat seperti di gambar.

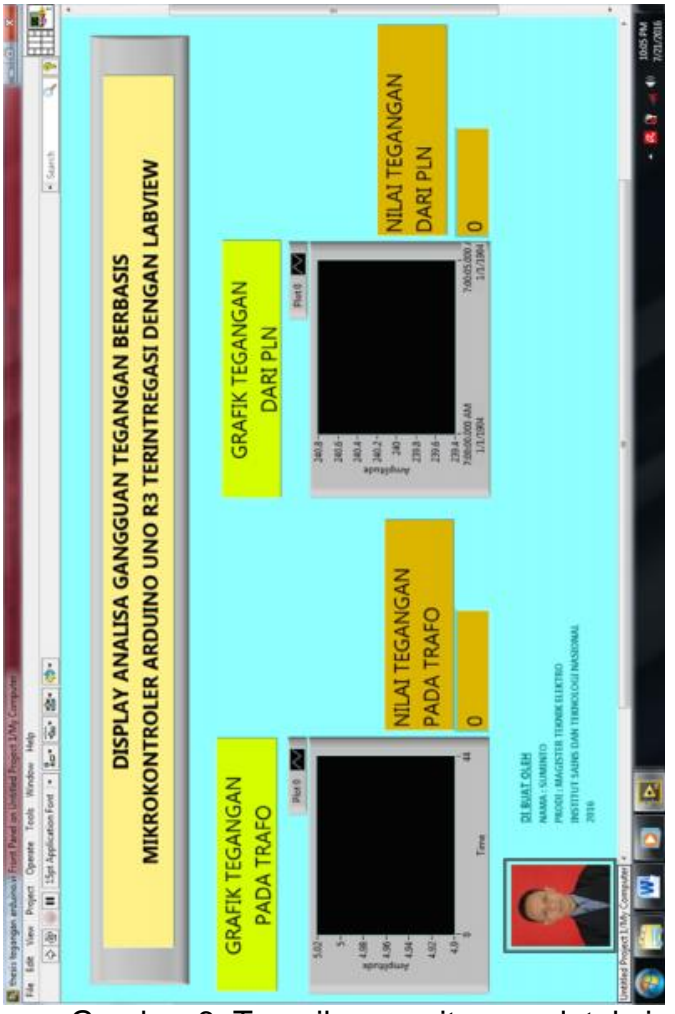

Gambar 6. Tampilan monitor pendeteksi gangguan tegangan berbasis arduino terintegrasi dengan Labview

Pada tampilan front panel (gambar3.9) akan menampilkan nilai tegangan secara real time dan datanya selalu terekam ke dalam memori PC atau laptop. Data yang masuk akan otomatis dalam bentuk file EXCEL sehingga memudahkan bagi kita untuk Mengolah data tersebut.

\section{HASIL DAN PEMBAHASAN}

\subsection{Hasil penelitian deteksi dan analisa gangguan tegangan berbasis Arduino UNO R3 dan Labview dengan tegangan real dari PLN tanpa tambahan beban di titik pengukuran.}

Pendeteksi gangguan tegangan berbasis arduino UNO R3 di tempat simulasinya dilakukan di Laboraturium mesin-mesin listrik Universitas Pamulang. Pengambilan data tegangan tersebut dilakukan secara real time dan dilakukan dalam durasi setiap 0,5detik. Rata-rata nilai tegangan hasil pengukuran tersebut adalah 216.74 Volt, untuk detail data hasil pengukuran tegangan 100 detik pertama dapat di lihat pada gambar 7 . 


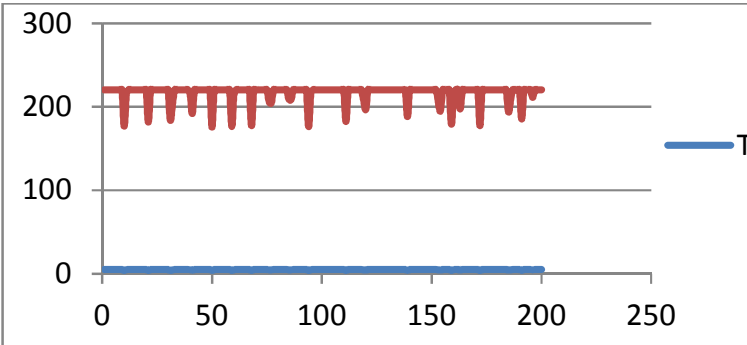

Gambar 7. Grafik deteksi tegangan PLN tanpa tambahan beban di titik pengukuran

\subsection{Hasil penelitian deteksi dan} analisa gangguan tegangan berbasis Arduino UNO R3 dan Labview tegangan real time dari PLN dengan tambahan beban Induktif di titik pengukuran.

Deteksi gangguan tegangan dari PLN juga dikombinasikan dengan menambahkan beban Induktif. Berikut ini adalah data tegangan PLN jika ditambahkan beban induktif 186,5 Watt dan posisi pengambilan data di tempatkan pada titik terakhir beban tersebut di ambil. Rata-rata nilai tegangan hasil pengukuran tersebut adalah 208.38 Volt.

Berikut adalah tampilan gambar grafik saat pengukuran tegangan dengan tambahan beban induktif di titik pengukuran.

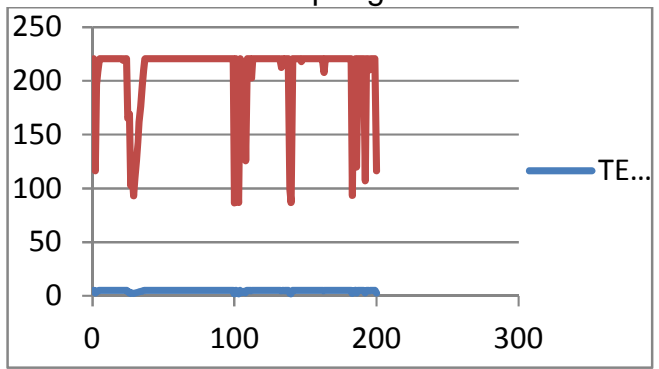

Gambar 8. Grafik deteksi tegangan PLN dengan tambahan beban induktif di titik pengukuran.

4.3 Hasil penelitian deteksi dan analisa gangguan tegangan berbasis Arduino UNO R3 dan Labview tegangan real time dari PLN dengan tambahan beban kapasitif di titik pengukuran.

Deteksi gangguan tegangan dari PLN juga dilakukan dengan menambahkan beban kapasitif. Berikut ini adalah data tegangan PLN

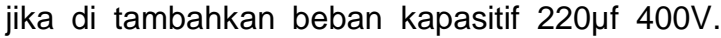
Posisi pengambilan data di tempatkan pada titik terakhir beban tersebut diambil. Rata-rata nilai tegangan hasil pengukuran tersebut adalah 211.25 Volt, sedangkan detail hasil pengukuran tegangan 100 detik pertama dapat di lihat pada gambar 9 .

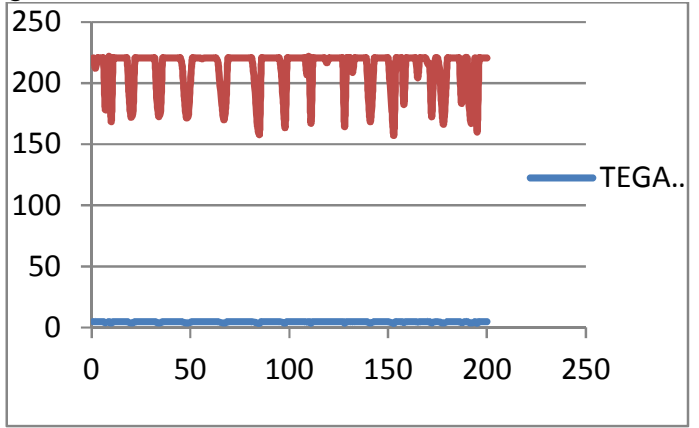

Gambar 9. Grafik deteksi tegangan PLN dengan tambahan beban kapasitif di titik pengukuran.

4.4 Hasil penelitian deteksi dan analisa gangguan tegangan berbasis Arduino UNO R3 dan Labview tegangan real time dari PLN dengan tambahan beban resistif di titik pengukuran.

Dalam analisa ini deteksi gangguan tegangan dari PLN juga di kombinasikan dengan menambahkan beban resistif. Berikut ini adalah data tegangan PLN jika di tambahkan beban resistif $300 \mathrm{~W}$. Rata-rata nilai tegangan hasil pengukuran tersebut adalah 210.95 Volt. Posisi pengambilan data di tempatkan pada titik terakhir beban tersebut di ambil. Detail gradik pengukuran tegangan dapat di lihat pada gambar 10.

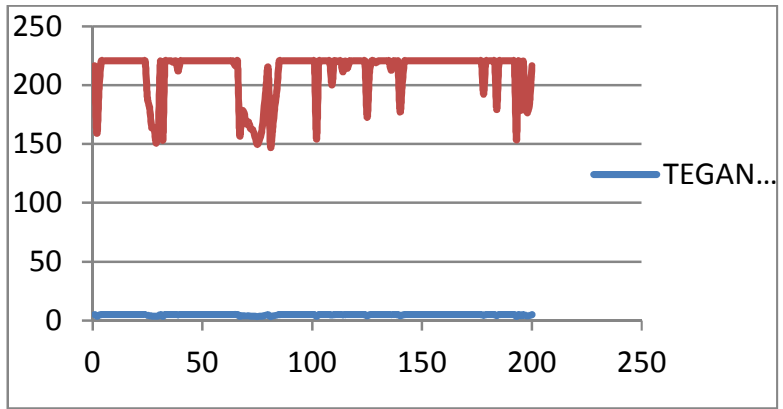

Gambar 10. Grafik deteksi tegangan PLN dengan tambahan beban resistif di titik pengukuran 
4.5 Hasil perbandingan deteksi dan analisa gangguan tegangan berbasis Arduino UNO R3 dan Labview tegangan real time dari PLN dengan tanpa beban tambahan, dengan tambahan beban induktif, dengan tambahan beban kapasitif dan dengan tambahan beban resistif di titik pengukuran.

Setelah melakukan pengukuran data tegangan tanpa menggunakan tambahan beban, menggunakan tambahan beban induktif, menggunakan tambahan beban kapasitif dan menggunakan beban tambahan resistif. Hasil pengukuran tersebut di bandingkan. Perbandingan hasil pengukuran data tegangan tersebut bisa dilihat pada gambar 11 .

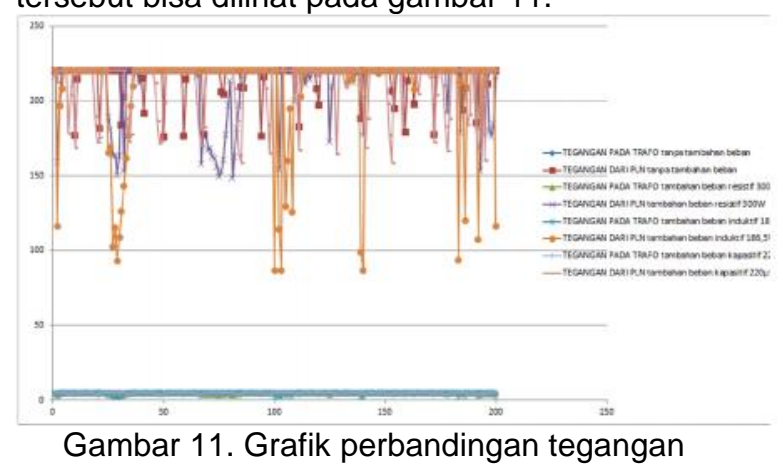

\section{KESIMPULAN}

Dari hasil penelitian dan analisa deteksi gangguan tegangan berbasis Arduino UNO R3 yang terintregasi dengan Labview tersebut dapat ditarik kesimpulan.

Alat Pendeteksi gangguan tegangan sudah dapat digunakan sesuai dengan fungsinya, yaitu melakukan pengukuran tegangan secara kontinue dan real time. Selain dapat melakukan pengukuran tegangan dengan akurat, data pengukuran tegangan dapat tersimpan dalam harddisck atau memori laptop.

Dari hasil pengukuran, Tegangan yang diterima yang terlihat normal ternyata ada gangguan tegangan turun atau naik, namun karena waktu yang begitu cepat (dalam hitungan 0,5 detik) sehingga konsumen tidak menyadari tentang adanya gangguan tegangan tersebut. Apabila melakukan pengukuran tegangan dengan mengganti jenis beban yang berbeda (beban pada area titik yang di ukur) maka gangguan yang terdeteksi pada alat ukur juga berbeda, dan didapat hasil akhir rata-rata nilai tegangan tanpa tambahan beban di titik pengukuran $=216.74$ Volt , jika ditambahkan beban induktif di titik pengukuran $=208.38$ Volt, jika ditambahkan beban kapasitif di titik pengukuran $=211.25$ Volt, jika ditambahkan beban resistif di titik pengukuran $=210.95$ Volt. Dari hasil pengukuran tersebut didapat bahwa beban induktif sangat berpengaruh terhadap terjadinya penurunan tegangan.

\section{DAFTAR REFERENSI}

[1] H. Kurniawan, D. M. Informatika, J. S. Komputer, and K. Cahaya, "Jurnal TEKNOIF ISSN : 2338-2724 IMPLEMENTASI SISTEM KENDALI CAHAYA DAN SIRKULASI UDARA RUANGAN DENGAN MEMANFAATKAN PC DAN MIKROKONTROLER," ISSN 2338-2724, vol. 3, no. 1, pp. 12-19, 2015.

[2] R. Santos, 18+RANDOM NERD TUTORIALS PROJECT, no. 2010. 2010.

[3] A. F. Silvia, E. Haritman, and Y. Muladi, "RANCANG BANGUN AKSES KONTROL PINTU GERBANG BERBASIS ARDUINO DAN ANDROID," http//jurnal.upi.edu/electrans (1 ISSN 1412 - 3762), vol. 13, no. 1, pp. 1-10, 2014.

[4] S. MONK, PROJECTS FOR THE EVIL GENIUS (ISBN: 978-0-07-174134-7). Mc Graw Hill Companies, Inc, 2010.

[5] Hainur Rasjid Achmadi, Generator \& Transformer, BAGIAN PROYEK PENGEMBANGAN KURIKULUM DIREKTORAT PENDIDIKAN MENENGAH KEJURUAN DIREKTORAT JENDERAL PENDIDIKAN DASAR DAN MENENGAH DEPARTEMEN PENDIDIKAN NASIONAL 2004. Jakarta, Indonesia, 2004.

[6] James H. Harlow, ELECTRIC PAWER TRANSFORMER ENGINEERING (ISBN:0849317045). Boca Raton, Florida 33431.: Mariesa Crow, 2004.

[7] H. L. Willis, E. Power, C. Engineering, and W. A. Thue, Transformer Engineering: Design and Practice (ISBN:0824756533). 270 Madison Avenue, New York, USA: Marcel Dekker, Inc, 2004.

[8] N. S. Nise, Control Systems Engineering, 6th Edition. 2010.

[9] M. Dekker, Transformer Engineering_Design \& Practice-Kulkarni+Khaparde (ISBN:0824756533). New York USA: Marcel Dekker, Inc., 2004.

[10] L. Programming and B. One, LabVIEW Course (ISBN:0217863531). Jakarta, Indonesia, 2010. 


\section{LAMPIRAN:}

\begin{tabular}{|c|c|c|c|c|}
\hline $\begin{array}{l}\text { Time } \\
\text { setiap } \\
0,5 \\
\text { detik }\end{array}$ & $\begin{array}{l}\text { TEGANGAN } \\
\text { DARI PLN } \\
\text { tanpa } \\
\text { tambahan } \\
\text { beban di } \\
\text { titik } \\
\text { pengukuran }\end{array}$ & $\begin{array}{l}\text { TEGANGAN } \\
\text { DARI PLN } \\
\text { tambahan } \\
\text { beban } \\
\text { resistif } \\
300 \mathrm{~W} \text { di } \\
\text { titik } \\
\text { pengukuran }\end{array}$ & $\begin{array}{l}\text { TEGANGAN } \\
\text { DARI PLN } \\
\text { tambahan } \\
\text { beban } \\
\text { induktif } \\
\text { 186,5W di } \\
\text { titik } \\
\text { pengukuran }\end{array}$ & $\begin{array}{l}\text { TEGANGAN } \\
\text { DARI PLN } \\
\text { tambahan } \\
\text { beban } \\
\text { kapasitif } \\
220 \mu \mathrm{f} \text { di } \\
\text { titik } \\
\text { pengukuran }\end{array}$ \\
\hline 1 & 220.5588 & 216.4624 & 220.5588 & 220.5588 \\
\hline 2 & 220.5588 & 159.1128 & 116.424 & 212.1504 \\
\hline 3 & 220.5588 & 197.274 & 196.4116 & 220.5588 \\
\hline 4 & 220.5588 & 220.5588 & 208.2696 & 220.5588 \\
\hline 5 & 220.5588 & 220.5588 & 220.5588 & 220.5588 \\
\hline 6 & 220.5588 & 220.5588 & 220.5588 & 220.5588 \\
\hline 7 & 220.5588 & 220.5588 & 220.5588 & 178.3012 \\
\hline 8 & 220.5588 & 220.5588 & 220.5588 & 203.9576 \\
\hline 9 & 220.5588 & 220.5588 & 220.5588 & 220.5588 \\
\hline 10 & 176.792 & 220.5588 & 220.5588 & 168.3836 \\
\hline 11 & 214.7376 & 220.5588 & 220.5588 & 220.5588 \\
\hline 12 & 220.5588 & 220.5588 & 220.5588 & 220.5588 \\
\hline 13 & 220.5588 & 220.5588 & 220.5588 & 220.5588 \\
\hline 14 & 220.5588 & 220.5588 & 220.5588 & 220.5588 \\
\hline 15 & 220.5588 & 220.5588 & 220.5588 & 220.5588 \\
\hline 16 & 220.5588 & 220.5588 & 220.5588 & 220.5588 \\
\hline 17 & 220.5588 & 220.5588 & 220.5588 & 220.5588 \\
\hline 18 & 220.5588 & 220.5588 & 220.5588 & 220.5588 \\
\hline 19 & 220.5588 & 220.5588 & 220.5588 & 189.9436 \\
\hline 20 & 220.5588 & 220.5588 & 220.5588 & 172.0488 \\
\hline 21 & 181.7508 & 220.5588 & 220.5588 & 175.4984 \\
\hline 22 & 220.5588 & 220.5588 & 219.0496 & 220.5588 \\
\hline 23 & 220.5588 & 220.5588 & 220.5588 & 220.5588 \\
\hline 24 & 220.5588 & 220.5588 & 220.5588 & 220.5588 \\
\hline 25 & 220.5588 & 189.0812 & 165.1496 & 220.5588 \\
\hline 26 & 220.5588 & 180.8884 & 169.0304 & 220.5588 \\
\hline 27 & 220.5588 & 163.856 & 102.6256 & 220.5588 \\
\hline 28 & 220.5588 & 163.4248 & 115.346 & 220.5588 \\
\hline 29 & 220.5588 & 150.7044 & 92.9236 & 220.5588 \\
\hline 30 & 220.5588 & 163.2092 & 109.0936 & 220.5588 \\
\hline 31 & 184.1224 & 220.5588 & 126.3416 & 220.5588 \\
\hline 32 & 202.664 & 153.076 & 142.9428 & 220.5588 \\
\hline 33 & 220.5588 & 220.5588 & 161.9156 & 188.2188 \\
\hline 34 & 220.5588 & 220.5588 & 176.3608 & 172.6956 \\
\hline 35 & 220.5588 & 220.5588 & 196.6272 & 177.6544 \\
\hline 36 & 220.5588 & 220.5588 & 209.7788 & 220.5588 \\
\hline 37 & 220.5588 & 219.2652 & 220.5588 & 220.5588 \\
\hline 38 & 220.5588 & 220.5588 & 220.5588 & 220.5588 \\
\hline 39 & 220.5588 & 211.9348 & 220.5588 & 220.5588 \\
\hline 40 & 214.9532 & 220.5588 & 220.5588 & 220.5588 \\
\hline 41 & 191.884 & 220.5588 & 220.5588 & 220.5588 \\
\hline 42 & 220.5588 & 220.5588 & 220.5588 & 220.5588 \\
\hline 43 & 220.5588 & 220.5588 & 220.5588 & 220.5588 \\
\hline
\end{tabular}

\begin{tabular}{|c|c|c|c|c|}
\hline 44 & 220.5588 & 220.5588 & 220.5588 & 220.5588 \\
\hline 45 & 220.5588 & 220.5588 & 220.5588 & 220.5588 \\
\hline 46 & 220.5588 & 220.5588 & 220.5588 & 211.9348 \\
\hline 47 & 220.5588 & 220.5588 & 220.5588 & 186.7096 \\
\hline 48 & 220.5588 & 220.5588 & 220.5588 & 171.6176 \\
\hline 49 & 220.5588 & 220.5588 & 220.5588 & 173.3424 \\
\hline 50 & 175.714 & 220.5588 & 220.5588 & 198.7832 \\
\hline 51 & 220.5588 & 220.5588 & 220.5588 & 220.5588 \\
\hline 52 & 220.5588 & 220.5588 & 220.5588 & 220.5588 \\
\hline 53 & 220.5588 & 220.5588 & 220.5588 & 220.5588 \\
\hline 54 & 220.5588 & 220.5588 & 220.5588 & 220.5588 \\
\hline 55 & 220.5588 & 220.5588 & 220.5588 & 220.5588 \\
\hline 56 & 220.5588 & 220.5588 & 220.5588 & 219.912 \\
\hline 57 & 220.5588 & 220.5588 & 220.5588 & 220.5588 \\
\hline 58 & 220.5588 & 220.5588 & 220.5588 & 220.5588 \\
\hline 59 & 176.5764 & 220.5588 & 220.5588 & 220.5588 \\
\hline 60 & 214.522 & 220.5588 & 220.5588 & 220.5588 \\
\hline 61 & 220.5588 & 220.5588 & 220.5588 & 220.5588 \\
\hline 62 & 220.5588 & 220.5588 & 220.5588 & 220.5588 \\
\hline 63 & 220.5588 & 220.5588 & 220.5588 & 220.5588 \\
\hline 64 & 220.5588 & 220.5588 & 220.5588 & 216.8936 \\
\hline 65 & 220.5588 & 216.4624 & 220.5588 & 198.1364 \\
\hline 66 & 220.5588 & 220.5588 & 220.5588 & 181.9664 \\
\hline 67 & 220.5588 & 157.8192 & 220.5588 & 169.8928 \\
\hline 68 & 177.4388 & 178.3012 & 220.5588 & 182.182 \\
\hline 69 & 220.5588 & 176.5764 & 220.5588 & 220.5588 \\
\hline 70 & 220.5588 & 167.09 & 220.5588 & 220.5588 \\
\hline 71 & 220.3432 & 168.5992 & 220.5588 & 220.5588 \\
\hline 72 & 220.5588 & 162.9936 & 220.5588 & 220.5588 \\
\hline 73 & 220.5588 & 161.9156 & 220.5588 & 220.5588 \\
\hline 74 & 220.5588 & 156.0944 & 220.5588 & 220.5588 \\
\hline 75 & 220.5588 & 149.6264 & 220.5588 & 220.5588 \\
\hline 76 & 205.898 & 153.5072 & 220.5588 & 220.5588 \\
\hline 77 & 204.6044 & 160.4064 & 220.5588 & 220.5588 \\
\hline 78 & 220.5588 & 177.6544 & 220.5588 & 220.5588 \\
\hline 79 & 220.5588 & 197.274 & 220.5588 & 220.5588 \\
\hline 80 & 220.5588 & 213.444 & 220.5588 & 220.5588 \\
\hline 81 & 220.5588 & 148.5484 & 220.5588 & 220.5588 \\
\hline 82 & 220.5588 & 162.778 & 220.5588 & 208.2696 \\
\hline 83 & 220.5588 & 181.5352 & 220.5588 & 186.7096 \\
\hline 84 & 220.5588 & 197.0584 & 220.5588 & 163.856 \\
\hline 85 & 209.3476 & 220.5588 & 220.5588 & 158.466 \\
\hline 86 & 208.4852 & 220.5588 & 220.5588 & 220.5588 \\
\hline 87 & 220.5588 & 220.5588 & 220.5588 & 220.5588 \\
\hline 88 & 220.5588 & 220.5588 & 220.5588 & 220.5588 \\
\hline 89 & 220.5588 & 220.5588 & 220.5588 & 220.5588 \\
\hline 90 & 220.5588 & 220.5588 & 220.5588 & 220.5588 \\
\hline 91 & 220.5588 & 220.5588 & 220.5588 & 220.5588 \\
\hline 92 & 220.5588 & 220.5588 & 220.5588 & 220.5588 \\
\hline 93 & 220.5588 & 220.5588 & 220.5588 & 220.5588 \\
\hline 94 & 176.3608 & 220.5588 & 220.5588 & 220.5588 \\
\hline 95 & 216.0312 & 220.5588 & 220.5588 & 220.5588 \\
\hline 96 & 220.5588 & 220.5588 & 220.5588 & 208.2696 \\
\hline 97 & 220.5588 & 220.5588 & 220.5588 & 183.6912 \\
\hline 98 & 220.5588 & 220.5588 & 220.5588 & 164.7184 \\
\hline 99 & 220.5588 & 220.5588 & 220.5588 & 220.5588 \\
\hline 100 & 220.5588 & 220.5588 & 86.4556 & 220.5588 \\
\hline 101 & 220.5588 & 220.5588 & 220.5588 & 220.5588 \\
\hline 102 & 220.5588 & 154.154 & 114.0524 & 220.5588 \\
\hline 103 & 220.5588 & 220.5588 & 86.6712 & 220.5588 \\
\hline 104 & 220.5588 & 220.5588 & 220.5588 & 220.5588 \\
\hline 105 & 220.5588 & 220.5588 & 129.36 & 220.5588 \\
\hline 106 & 220.5588 & 220.5588 & 160.1908 & 220.5588 \\
\hline 107 & 220.5588 & 220.5588 & 194.9024 & 220.5588 \\
\hline 108 & 220.5588 & 220.5588 & 125.6948 & 220.5588 \\
\hline 109 & 220.5588 & 200.0768 & 220.5588 & 206.7604 \\
\hline 110 & 220.5588 & 220.5588 & 220.5588 & 220.5588 \\
\hline 111 & 182.6132 & 220.1276 & 220.5588 & 167.09 \\
\hline
\end{tabular}

Suminto. 


\begin{tabular}{|c|c|c|c|c|c|c|c|c|c|}
\hline 112 & 220.5588 & 220.5588 & 202.664 & 220.5588 & 180 & 220.5588 & 220.5588 & 220.5588 & 220.5588 \\
\hline 113 & 220.5588 & 220.5588 & 220.5588 & 220.5588 & 181 & 220.5588 & 220.5588 & 220.5588 & 220.5588 \\
\hline 114 & 220.5588 & 211.288 & 220.5588 & 220.5588 & 182 & 220.5588 & 220.5588 & 220.5588 & 220.5588 \\
\hline 115 & 220.5588 & 220.5588 & 220.5588 & 220.5588 & 183 & 220.5588 & 220.5588 & 93.3548 & 220.5588 \\
\hline 116 & 220.5588 & 214.3064 & 220.5588 & 220.5588 & 184 & 220.5588 & 179.1636 & 212.1504 & 220.5588 \\
\hline 117 & 220.5588 & 220.5588 & 220.5588 & 220.5588 & 185 & 193.8244 & 220.5588 & 220.5588 & 220.5588 \\
\hline 118 & 220.5588 & 220.5588 & 220.5588 & 220.5588 & 186 & 208.7008 & 220.5588 & 119.8736 & 220.5588 \\
\hline 119 & 208.2696 & 220.5588 & 220.5588 & 216.678 & 187 & 220.5588 & 220.5588 & 220.5588 & 184.1224 \\
\hline 120 & 196.8428 & 220.5588 & 220.5588 & 220.5588 & 188 & 220.5588 & 220.5588 & 220.5588 & 190.5904 \\
\hline 121 & 220.5588 & 220.5588 & 220.5588 & 220.5588 & 189 & 220.5588 & 220.5588 & 220.5588 & 220.5588 \\
\hline 122 & 220.5588 & 220.5588 & 220.5588 & 220.5588 & 190 & 220.5588 & 220.5588 & 220.5588 & 220.5588 \\
\hline 123 & 220.5588 & 220.5588 & 220.5588 & 220.5588 & 191 & 185.416 & 220.5588 & 220.5588 & 181.5352 \\
\hline 124 & 220.5588 & 220.5588 & 220.5588 & 220.5588 & 192 & 220.5588 & 220.5588 & 107.1532 & 167.09 \\
\hline 125 & 220.5588 & 172.6956 & 220.5588 & 220.5588 & 193 & 220.5588 & 153.2916 & 220.5588 & 176.792 \\
\hline 126 & 220.5588 & 209.132 & 220.5588 & 220.5588 & 194 & 220.5588 & 220.5588 & 220.5588 & 220.5588 \\
\hline 127 & 220.5588 & 220.5588 & 220.5588 & 220.5588 & 195 & 220.5588 & 178.5168 & 210.21 & 159.9752 \\
\hline 128 & 220.5588 & 220.5588 & 220.5588 & 164.2872 & 196 & 211.288 & 220.5588 & 220.5588 & 220.5588 \\
\hline 129 & 220.5588 & 219.0496 & 220.5588 & 220.5588 & 197 & 220.5588 & 180.2416 & 220.5588 & 220.5588 \\
\hline 130 & 220.5588 & 220.5588 & 220.5588 & 220.5588 & 198 & 220.5588 & 176.5764 & 220.5588 & 220.5588 \\
\hline 131 & 220.5588 & 220.5588 & 220.5588 & 220.5588 & 199 & 220.5588 & 184.9848 & 220.5588 & 220.5588 \\
\hline 132 & 220.5588 & 220.5588 & 220.5588 & 208.7008 & 200 & 220.5588 & 216.4624 & 116.424 & 220.5588 \\
\hline 133 & 220.5588 & 220.5588 & 212.5816 & 220.5588 & & & & & \\
\hline 134 & 220.5588 & 220.5588 & 220.5588 & 220.5588 & & & & & \\
\hline 135 & 220.5588 & 220.5588 & 214.522 & 220.5588 & & & & & \\
\hline 136 & 220.5588 & 212.5816 & 220.5588 & 220.5588 & & & & & \\
\hline 137 & 220.5588 & 220.5588 & 220.5588 & 220.5588 & & & & & \\
\hline 138 & 219.912 & 218.834 & 220.5588 & 220.5588 & & & & & \\
\hline 139 & 188.2188 & 220.5588 & 98.7448 & 220.5588 & & & & & \\
\hline 140 & 220.5588 & 177.4388 & 86.6712 & 188.65 & & & & & \\
\hline 141 & 220.5588 & 201.1548 & 220.5588 & 168.3836 & & & & & \\
\hline 142 & 220.5588 & 220.5588 & 220.5588 & 188.0032 & & & & & \\
\hline 143 & 220.5588 & 220.5588 & 220.5588 & 220.5588 & & & & & \\
\hline 144 & 220.5588 & 220.5588 & 220.5588 & 220.5588 & & & & & \\
\hline 145 & 220.5588 & 220.5588 & 220.5588 & 220.5588 & & & & & \\
\hline 146 & 220.5588 & 220.5588 & 220.5588 & 220.5588 & & & & & \\
\hline 147 & 220.5588 & 220.5588 & 217.9716 & 220.5588 & & & & & \\
\hline 148 & 220.5588 & 220.5588 & 220.5588 & 220.5588 & & & & & \\
\hline 149 & 220.5588 & 220.5588 & 220.5588 & 220.5588 & & & & & \\
\hline 150 & 220.5588 & 220.5588 & 220.5588 & 220.5588 & & & & & \\
\hline 151 & 220.5588 & 220.5588 & 220.5588 & 198.352 & & & & & \\
\hline 152 & 220.5588 & 220.5588 & 220.5588 & 176.792 & & & & & \\
\hline 153 & 206.3292 & 220.5588 & 220.5588 & 158.6816 & & & & & \\
\hline 154 & 195.118 & 220.5588 & 220.5588 & 220.5588 & & & & & \\
\hline 155 & 220.5588 & 220.5588 & 220.5588 & 220.5588 & & & & & \\
\hline 156 & 220.5588 & 220.5588 & 220.5588 & 220.5588 & & & & & \\
\hline 157 & 220.5588 & 220.5588 & 220.5588 & 220.5588 & & & & & \\
\hline 158 & 220.5588 & 220.5588 & 220.5588 & 182.3976 & & & & & \\
\hline 159 & 179.1636 & 220.5588 & 220.5588 & 220.5588 & & & & & \\
\hline 160 & 213.6596 & 220.5588 & 220.5588 & 220.5588 & & & & & \\
\hline 161 & 220.5588 & 220.5588 & 220.5588 & 220.5588 & & & & & \\
\hline 162 & 220.5588 & 220.5588 & 220.5588 & 220.5588 & & & & & \\
\hline 163 & 197.4896 & 220.5588 & 207.6228 & 220.5588 & & & & & \\
\hline 164 & 220.5588 & 220.5588 & 220.5588 & 220.5588 & & & & & \\
\hline 165 & 220.5588 & 220.5588 & 220.5588 & 204.3888 & & & & & \\
\hline 166 & 220.5588 & 220.5588 & 220.5588 & 220.5588 & & & & & \\
\hline 167 & 220.5588 & 220.5588 & 220.5588 & 220.5588 & & & & & \\
\hline 168 & 220.5588 & 220.5588 & 220.5588 & 220.5588 & & & & & \\
\hline 169 & 220.5588 & 220.5588 & 220.5588 & 220.5588 & & & & & \\
\hline 170 & 220.5588 & 220.5588 & 220.5588 & 215.8156 & & & & & \\
\hline 171 & 220.5588 & 220.5588 & 220.5588 & 216.0312 & & & & & \\
\hline 172 & 177.4388 & 220.5588 & 220.5588 & 172.48 & & & & & \\
\hline 173 & 220.5588 & 220.5588 & 220.5588 & 204.1732 & & & & & \\
\hline 174 & 220.5588 & 220.5588 & 220.5588 & 220.5588 & & & & & \\
\hline 175 & 220.5588 & 220.5588 & 220.5588 & 220.5588 & & & & & \\
\hline 176 & 220.5588 & 220.5588 & 220.5588 & 210.4256 & & & & & \\
\hline 177 & 220.5588 & 220.5588 & 220.5588 & 183.0444 & & & & & \\
\hline 178 & 220.5588 & 192.3152 & 220.5588 & 166.2276 & & & & & \\
\hline 179 & 220.5588 & 220.5588 & 220.5588 & 188.0032 & & & & & \\
\hline
\end{tabular}

Suminto. 